\title{
Impact of Spirituality on Depression, Anxiety and Stress of Students Preparing for Competitive Exams
}

\author{
Manpreet $\mathrm{Ola}^{1 *}$
}

\section{ABSTRACT}

Background: Gradually over the years trend towards education system in our country has changed, it has become highly competitive. On the basis of one's grades admissions to various "top colleges" is provided, which further leads to "high packaged placements". On the basis of one's job status and college ranking their self worth is measured and all this puts lot of burden on students who have to continuously strive to achieve better than their batch mates, their siblings, relatives, neighbors etc. Aim: The aim of the study was to see whether spirituality would have any impact on depression, anxiety and stress in male and female students preparing for competitive exams. Methods: Participants were 60 students (30 males and 30 females) from areas of Rajasthan and Delhi, India, in the age range of 16-25 years, with no history of any psychiatric illness. They gave their consent to participate in the study. Spirituality was assessed using the daily spiritual experience scale by Underwood \& Teresi, (2002), depression, anxiety, and stress levels through Depression, Anxiety, Stress Scales (DASS by Lovibond \& Lovibond, 1995). Sample was purposive and the data were collected in individual situations. Results: There was difference between male and female students with regard to spirituality, depression, anxiety and stress, however only on the dimension of anxiety the results were significant, where female students had significantly more anxiety than that of male students $(\mathrm{t}=2.87, \mathrm{p}=.01)$. With regard to correlation between spirituality, depression, anxiety and stress there was significant inverse correlation for male and female students. However only for anxiety scores in females, there was a significant inverse correlation $(\mathrm{r}=-.417, \mathrm{p}=.01)$. Conclusion: It can be concluded that spirituality to some extent helps in reducing anxiety. At the same time it is essential for us to realize that spirituality is not the only way to help the young stressed students to cope with this life challenge, the family simultaneously needs to be supportive and not over pressurize the students and should stop comparing them to one or the other. However due to the small sample size the result findings cannot be generalized.

Keywords: Mental Health, Spirituality, Depression, anxiety and Stress.

\footnotetext{
${ }^{1}$ Assistant Professor at Amity University Gurgaon, Haryana, India *Responding Author

(C) 2016 I M Ola; licensee IJIP. This is an Open Access Research distributed under the terms of the Creative Commons Attribution License (http://creativecommons.org/licenses/by/2.0), which permits unrestricted use, distribution, and reproduction in any Medium, provided the original work is properly cited.
} 
A sense of competition for good results, grades and good jobs is noticed at all levels of education and work life in every country however due to increasing suicide rates in our country in the recent past, has highlighted the urgent need to emphasize the seriousness of this domain and suggest the various remedies to combat and minimize the rising deaths of the young individuals.

Mental health of students: Nowadays stress is considered to be a part of the student's life and can has been seen to have an impact on the students coping strategies in accord with the demands of academic life. Research studies have found a strong relationship between stressful life events and reduced academic performance and between health's related well being (Misra \& McKean, 2000). It has been studied over time that moderate level of stress experienced by students may be required and is even advantageous for them to succeed in their endeavors (Larson, 2006). However an excessive amount of stress may devastate them and lead to anxiety, depression, physical illness, and long term physical and psychological health problems (Larson, 2006). Another study conducted by Misra and Castillo in 2004 concluded that perception and reaction to stress is different in both genders i.e. males and females. Sulaiman, Hassan, Sapian and Abdullah (2009) also found that males and female students experience different level of stress and this is because females are more likely to be emotional than males in reaction to their environment. However this is specifically seen that greater levels of stress and more health problems are found in females than their male counterparts (Hall et al., 2006). Females are also more likely to have lower tolerance to mental illnesses than males.

\section{METHODS:}

Aim:

The aim of the study was to see whether spirituality would have any impact on depression, anxiety and stress in male and female students preparing for competitive exams.

\section{Hypotheses:}

H1: There would be a significant difference between male and female students on spirituality, depression, anxiety and stress.

H2: Spirituality would have an inverse correlation with depression, anxiety and stress.

\section{Research design and variables:}

Two groups research design was used for the study. Independent variable of the study was spirituality. Dependent variables of the study were depression, anxiety and stress.

\section{Sample and sampling:}

Purposive sample consisted of 60 students preparing for competitive exams (30 males and 30 females) who filled the informed consent form to participate in the study. Their age range was 16-25 years. The participants had no history of any psychiatric illness. Participants who were not 
fluent in English or Hindi were excluded from the study. The data was collected from areas of Rajasthan and Delhi, India.

\section{Tools used in the study:}

Personal data sheet: To record relevant personal information on of the participants.

Depression, anxiety and stress scale (DASS by Lovibond \& Lovibond, 1995): It is a 42-item questionnaire which includes three self-report scales designed to measure the negative emotional states of depression, anxiety and stress. Each of the three scales contains 14 items, divided into subscales of 2-5 items with similar content. The Depression scale assesses dysphoria, hopelessness, devaluation of life, self-deprecation, lack of interest/ involvement, anhedonia, and inertia. The Anxiety scale assesses autonomic arousal, skeletal muscle effects, situational anxiety, and subjective experience of anxious affect. The Stress scale (items) is sensitive to levels of chronic non- specific arousal. It assesses difficulty relaxing, nervous arousal, and being easily upset/ agitated, irritable/ over-reactive and impatient. Respondents are asked to use 4-point severity/ frequency scales to rate the extent to which they have experienced each state over the past week. The reliabilities (internal consistencies) of this scale as measured by Cronbach's are 0.90 for the anxiety scale, 0.95 for the depression scale, 0.93 for the stress scale and 0.97 for the total score.

Daily spiritual experience scale: DSES by Underwood \& Teresi, (2002) was used to assess spirituality; it is a 16-item self-report scale for spiritual experience. It specifically aims to measure ordinary, daily spiritual experiences. The items of the questionnaire are measured on a 6-point Likert-type scale.

\section{RESULT AND DISCUSSION:}

As the hypotheses were guiding force for analysis of the data, results are displayed and discussed according to them.

H1: Difference between male and female students with regard to spirituality, depression, anxiety and stress. 
Impact of Spirituality on Depression, Anxiety and Stress of Students Preparing for Competitive Exams

Table No.1: Difference (t- Test) between male and female students for depression, anxiety, stress and spirituality $(N=60)$.

\begin{tabular}{|l|l|l|l|l|}
\hline \multirow{2}{*}{ DEPRESSION } & GROUPS & MEAN & S.D. & T- TEST \\
\hline \multirow{2}{*}{ ANXIETY } & MALE & 7.36 & 4.78 & \multirow{2}{*}{.906} \\
\cline { 2 - 4 } & FEMALE & 8.46 & 4.62 & \\
\hline \multirow{2}{*}{ STRESS } & MALE & 8.10 & 7.07 & \multirow{2}{*}{$\mathbf{2 . 8 7 * *}$} \\
\cline { 2 - 4 } & FEMALE & 12.79 & 8.53 & \\
\hline \multirow{2}{*}{ SPIRITUALITY } & MALE & 8.30 & 4.34 & \multirow{2}{*}{.604} \\
\cline { 2 - 4 } & FEMALE & 8.96 & 4.20 & \multirow{2}{*}{} \\
\cline { 2 - 4 } & MALE & 2.87 & .81 & \\
\cline { 2 - 4 } & FEMALE & 2.62 & .57 & \\
\hline
\end{tabular}

As we can clearly see from the results (table no. 1) that for all the dimensions of mental health such as depression, anxiety and stress males had scored slightly lower to their female counterparts, though the results were only significant for the anxiety dimension of mental health where females had scored a little higher than males. For spirituality on the other hand males had scored slightly higher than females. Our results are supported by research conducted by Watson (2002) on college students and academic stress with reference to gender differences. The results found non-significant difference in the perceived stress between male and female students. Studies have shown that it is not only academic burden that the students have to face there are various other several sources of stress for these students, such as being away from home, adapting to a new environment, where they are taking coaching classes, forming new social relationships, budgeting time and money, social obligations, and also adding cherry on the cake the rising academic demands (Hall et al., 2006). And all these new responsibilities, high expectations, and extreme demands may leave a student feeling overwhelmed with too many things to do, too much to achieve and too much to learn too quickly (Dyson \& Renk, 2006; Larson, 2006) causing mental health illnesses, providing support to our results.

H2: Correlation of spirituality with depression, anxiety and stress.

TABLE 2: Correlation of Spirituality with Depression, Anxiety and Stress in Male and Female Students $(N=60)$.

\begin{tabular}{|l|l|l|l|l|}
\hline \multirow{4}{*}{ SPIRITUALITY } & \multicolumn{2}{|c|}{ DEPRESSION } & ANXIETY & STRESS \\
\cline { 2 - 5 } & MALES & -.002 & -.063 & -.032 \\
\cline { 2 - 5 } & FEMALES & -.046 & $-.417^{* *}$ & -.017 \\
\hline
\end{tabular}


It is clearly apparent from table no.2, that our hypothesis regarding inverse relation between spirituality and depression, anxiety and stress has been proved, for both male and female students there has been inverse correlation, however only for anxiety with spirituality for female students there has been significant inverse relationship. As we can see from our results that though there is an inverse correlation between spirituality and the mental health dimensions our findings are not significant for most of the variables because it's essential at this point to understand that spiritual and religious practices are not, and should not be, seen as the only sole means to an end when trying to achieve and work towards better mental health.

\section{CONCLUSION}

1. In this study female students had scored significantly higher on the dimension of anxiety as compared to their male counterparts.

2. Results indicated that spirituality was inversely correlated with depression, anxiety and stress in students.

3. The studies presented here clearly show that spiritual practices can have slight impact on enhancing positive mental well being amongst students preparing for competitive exams for which there needs to increased awareness in these students, so that they start engaging themselves in spiritual practices.

4. Thus, this study can lend support to the growing body of work indicating that we should perhaps take seriously the rising burden created on students due to the academic pressures and desires to prove their worth.

5. Psychologists and mental health professionals should provide adequate guidance to care givers about the role played by social support in mental well being of these students.

6. It is essential that adequate measures are taken at policy making levels so that this rising competitiveness and death toll can be minimized to some extent.

\section{REFERENCES}

Dyson, R., \& Renk, K. (2006). Freshman adaptation to university life: depressive symptoms, stress, and coping. Journal of Clinical Psychology, 62(10), 1231-1244.

Hall, N. C., Chipperfield, J. G., Perry, R. P, Ruthig, J. C., \& Goetz, T. (2006). Primary and secondary control in academic development: gender-specific implications for stress and health in college students. Anxiety, Stress, and Coping, 19(2), 189-210.

Lovibond, S. H. \& Lovibond, P. F. (1995). Manual for the Depression Anxiety Stress Scales (2nd Edn.) Sydney: Psychology Foundation.

Misra, R. \& Castillo, L. G. (2004). Academic Stress among College Students: Comparison of American and International Students. International Journal of Stress Management, 11 (2), 132-148.

Misra, R. \& McKean, M. (2000). College students' academic stress and its relation to their anxiety, time management, and leisure satisfaction. American Journal of Health Studies, 16 (1): $41-52$. 
Sulaiman, T., Hassan, A., Sapian, V. M., \& Abdullah, S. K. (2009). The Level of Stress among Students in Urban and Rural Secondary Schools in Malaysia. European Journal of Social Sciences, 10(2), 179-184.

Underwood, L. G. \& Teresi, J. (2002). The Daily Spiritual Experience Scale: Development, theoretical description, reliability, exploratory factor analysis, and preliminary construct validity using health related data. Annals of Behavioral Medicine, 24, 22-33.

Watson, R. L. (2002). A comparison of perceived stress levels and coping styles of junior and senior students in nursing and social work programs. Unpublished doctoral dissertation, Marshall University, Huntington.

How to cite this article: M Ola (2016), Impact of Spirituality on Depression, Anxiety and Stress of Students Preparing for Competitive Exams, International Journal of Indian Psychology, Volume 3, Issue 3, No. 11, DIP: 18.01.193/20160303, ISBN: 978-1-365-21307-6 